\title{
Intestinal macrophages and response to microbial encroachment
}

\author{
PD Smith $^{1}$, LE Smythies ${ }^{1}$, R Shen ${ }^{1}$, T Greenwell-Wild ${ }^{2}$, M Gliozzi $^{2}$ and SM Wahl ${ }^{2}$
}

Macrophages in the gastrointestinal mucosa represent the largest pool of tissue macrophages in the body. In order to maintain mucosal homeostasis, resident intestinal macrophages uniquely do not express the lipopolysaccharide (LPS) co-receptor CD14 or the IgA (CD89) and IgG (CD16, 32, and 64) receptors, yet prominently display Toll-like receptors (TLRs) 3-9. Remarkably, intestinal macrophages also do not produce proinflammatory cytokines in response to TLR ligands, likely because of extracellular matrix (stromal) transforming growth factor- $\beta$ (TGF- $\beta$ ) dysregulation of

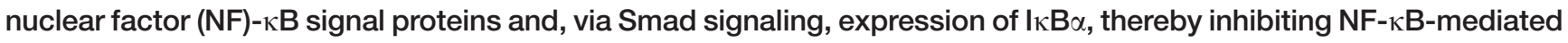
activities. Thus, in noninflamed mucosa, resident macrophages are inflammation anergic but retain avid scavenger and host defense function, an ideal profile for macrophages in close proximity to gut microbiota. In the event of impaired epithelial integrity during intestinal infection or inflammation, however, blood monocytes also accumulate in the lamina propria and actively pursue invading microorganisms through uptake and degradation of the organism and release of inflammatory mediators. Consequently, resident intestinal macrophages are inflammation adverse, but when the need arises, they receive assistance from newly recruited circulating monocytes.

\section{INTRODUCTION}

Intestinal and colonic macrophages represent the largest population of mononuclear phagocytes in the body. ${ }^{1}$ Located strategically in the subepithelial lamina propria in close proximity to huge numbers of lumenal bacteria and antigenic stimuli, gut macrophages regulate inflammatory responses to bacteria and antigens that breach the epithelium, protect the mucosa against harmful pathogens, and scavenge dead cells and foreign debris (Figure 1). In these effector roles, gut macrophages are part of the first-line defense mechanisms, referred to collectively as the innate immune system, with which the host responds to harmful microorganisms and their immunostimulatory products. ${ }^{2}$ These first-line mechanisms constitute an ancient host defense system that arose an estimated billion years ago in early multicellular organisms and are still utilized by protozoa, insects, plants, and animals. ${ }^{3}$ In animals, macrophages concentrate in the gastrointestinal mucosa, the body surface colonized shortly after birth by a multitude of microbial species, resulting in a microbe-mucosal ecosystem that contains over a hundred trillion bacteria in the adult gastrointestinal tract. ${ }^{4}$

In response to this crowded sea of microbes, innate host responses must distinguish nonharmful commensal organisms from those that pose a danger to the host. The gut epithelium typically provides a structural barrier to both commensals and pathogens and secretes a protective coat of mucus that contains antimicrobial peptides, including defensins and serine leukocyte protease inhibitor ${ }^{5,6}$ that restrict microbial translocation. When these impediments are breached through injury or infection, or when microorganisms undergo epithelial cell transcytosis or translocation via $\mathrm{M}$ cells or dendritic cells (DCs) (Figure 1), an array of subepithelial innate defense cells, especially mucosal macrophages, are poised for response. Such responses are rapid, initiated within minutes, and directed toward conserved structures in infectious agents that may cross the mucosal epithelium (Figure 1). Macrophage recognition of these patterns is mediated in part by pattern recognition receptors that include the germline-encoded transmembrane Toll-like receptors (TLRs) and the cytosolic NOD-like receptors, ${ }^{7,8}$ predetermined repertoires of molecules that recognize foreign carbohydrate, lipid, and nucleic acid ligands (pathogen-associated molecular patterns) essential for microbe survival, thereby limiting the diversity of ligands to which macrophages can respond. Predetermination comes at a price, however, as the innate immune system, which also includes polymorphonuclear leukocytes, natural killer cells,

${ }^{1}$ Department of Medicine (Gastroenterology) University of Alabama at Birmingham, Birmingham, Alabama, USA. ${ }^{2}$ Oral Infection and Immunity Branch, National Institute of Dental and Craniofacial Research, National Institutes of Health, Bethesda, Maryland, USA. Correspondence: PD Smith (pdsmith@uab.edu) or SM Wahl (smwahl@dir.nidcr.nih.gov) 


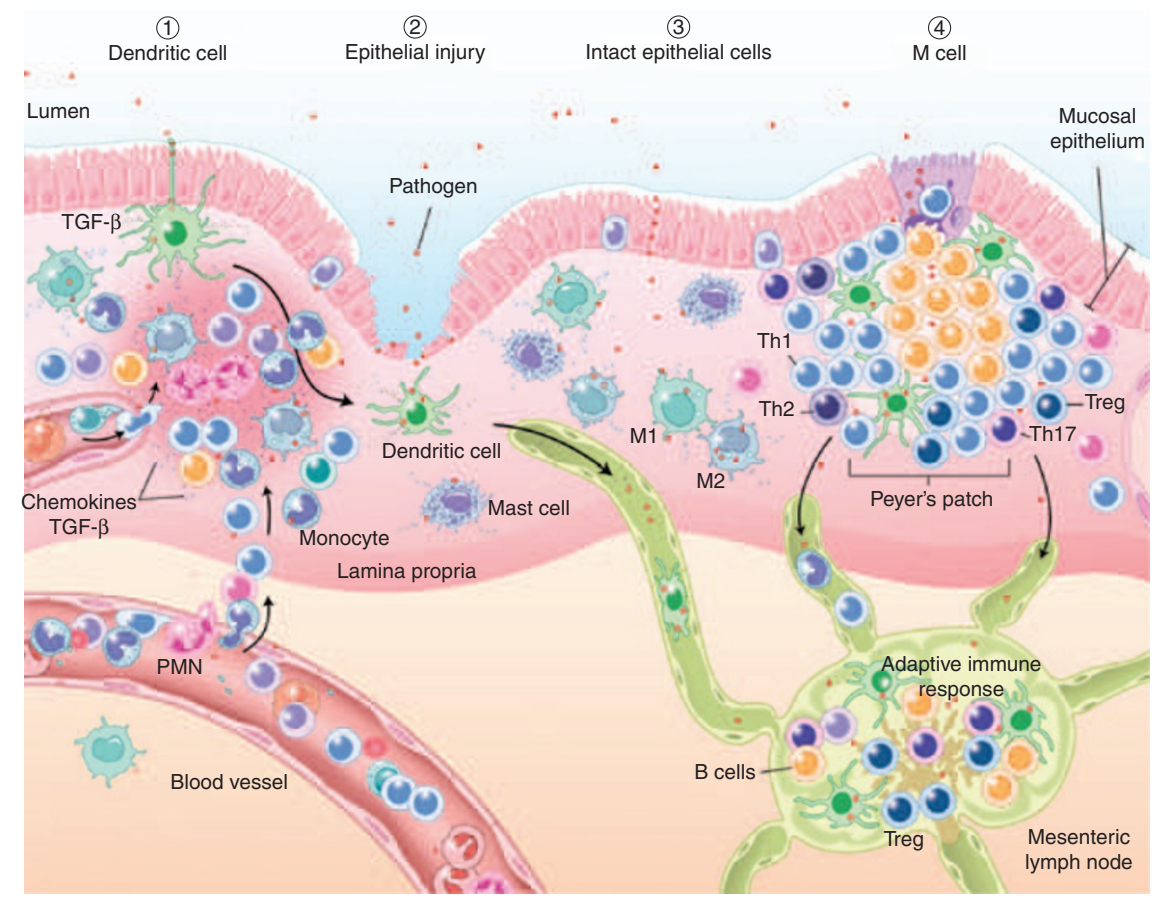

Figure 1 Mucosal exposure to pathogens and host response. The mucosal epithelium presents a formidable structural and chemical barrier to ill-intentioned microbes, which gain entry into the lamina propria (1) by dendritic cells, (2) through disrupted or injured epithelium, (3) between or through intact epithelial cells, and (4) through M cells. In noninflamed lamina propria, macrophages phagocytose and kill microbes without an inflammatory response. In the presence of inflammation and dysregulated mucosal homeostasis, newly recruited monocyte-derived macrophages (and other innate host defense cells) generate transforming growth factor- $\beta$ (TGF- $\beta$ ) and chemokines to recruit monocytes and other leukocyte populations to contain the infection. Microbes and/or their products are transported by dendritic cells in the lymphatics to draining lymph nodes where they induce an adaptive immune response. Failed clearance of the microbe and/or an inability to restore homeostatic regulation because of genetic and environmental factors can perpetuate inflammation locally and/or systemically (illustration by Lydia Kibiuk, NIH).

and DCs, cannot easily respond to novel molecules. Murine macrophages discriminate between pathogenic and nonpathogenic bacteria through a NOD-like receptor (NLRC4) that detects the type III secretion apparatus used by Gramnegative bacteria to inoculate virulence factors into cells, ${ }^{9}$ but whether human macrophages, and potentially mucosal macrophages, can distinguish between pathogenic and nonpathogenic bacteria is not known.

Complementing the innate system, but responding more slowly (hours to days), the acquired immune system of inducible defense mechanisms arose during the divergence of vertebrates from invertebrates, first in jawless vertebrates such as the lamprey and hagfish $\sim 500$ million years ago, ${ }^{10}$ and then in jawed vertebrates $\sim 400$ million years ago. ${ }^{11}$ Variations of this host defense system are present in fish, amphibians, reptiles, birds, and mammals, but not in invertebrates. The $\mathrm{T}$ and $\mathrm{B}$ lymphocytes of the acquired immune system utilize antigen-specific receptors and immunoglobulins (Igs), respectively, to recognize antigenic epitopes. In contrast to the evolutionarily conserved genes for innate response receptors, ${ }^{12}$ the genes for antigen-specific receptors undergo somatic recombination, enhancing ligand diversity. Immunologic memory is a key feature of the adaptive, but not the innate, immune system. Macrophages, along with DCs, present foreign antigens to cells of the acquired immune system, thereby integrating the innate and acquired systems for quick, yet broad, responses to microorganisms and antigens. The role of gut macrophages in antigen presentation, however, has not been thoroughly explored. Therefore, this review focuses on the host effector functions of gut macrophages.

\section{SOURCE OF MUCOSAL MACROPHAGES}

All tissue macrophages are derived from bone marrow stem cells through a highly regulated cascade of differentiation events $^{13,14}$ (Figure 2). In the bone marrow, a combination of cytokines that include interleukin (IL)-1, IL-3, and IL-6 stimulates stem cell heteromitosis, resulting in a pluripotent granulocyte/erythrocyte/megakaryocyte/macrophage colonyforming unit. In the continued presence of IL-1 and IL-3, this precursor develops into the progenitor for both granulocytes and macrophages, referred to as a granulocyte-macrophage colony-forming unit. IL-3 and granulocyte/macrophage colony stimulating factor (GM-CSF) induce proliferation of both granulocyte and monocyte precursors, whereas IL-1, IL-3, and $\mathrm{M}-\mathrm{CSF}$ induce the proliferation and differentiation of monocyte precursors. The continued presence of M-CSF, together with GM-CSF and IL-3, induces further differentiation of the monocyte precursor into a monoblast, then promonocyte, and finally a monocyte. Under homeostatic conditions, a single $\left(\mathrm{CD} 117^{+} \mathrm{CX}_{3} \mathrm{CR} 1^{+}\right)$murine precursor can develop into a monocyte or $\mathrm{DC},{ }^{15}$ but differentiation can be redirected under appropriate circumstances, such as tissue inflammation. In addition to cytokine growth factors, transcription factors are involved in macrophage differentiation. ${ }^{16}$ These factors include PU.1 and AML1, which control myeloid cell development. ${ }^{17}$ 


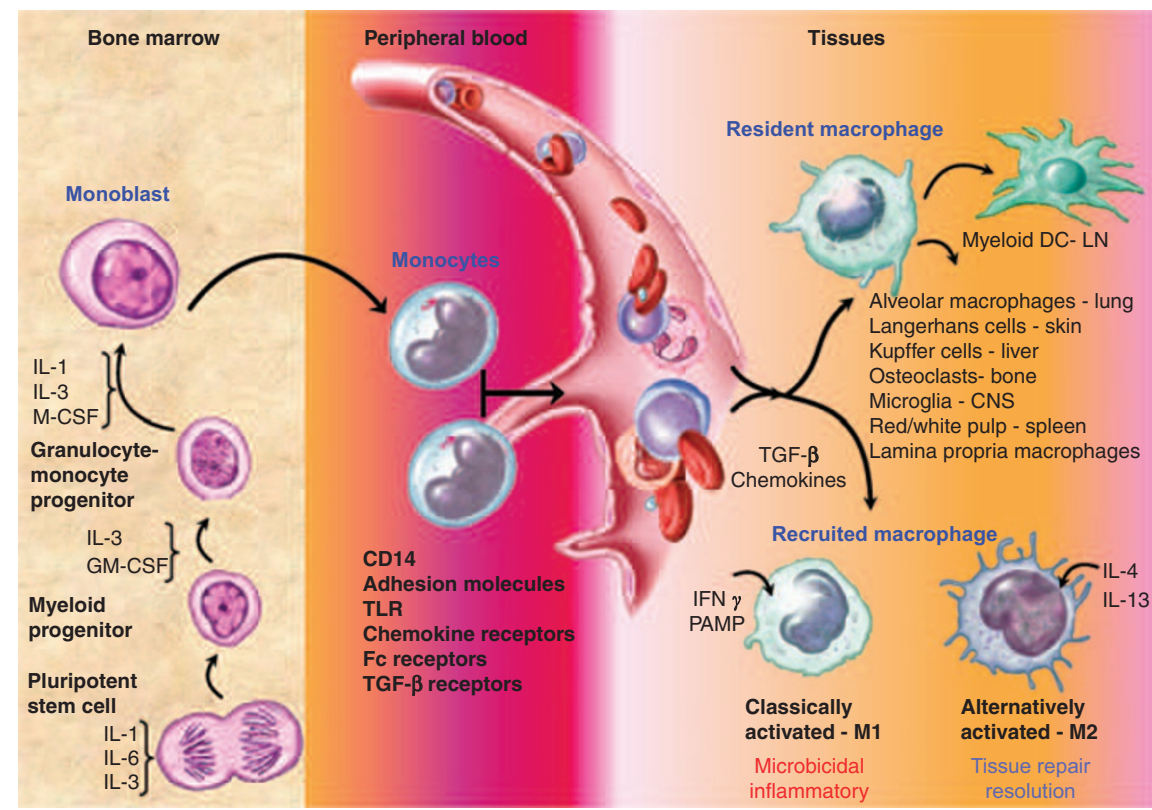

Figure 2 Myeloid cell recruitment, activation, and regulation. Pluripotent stem cells differentiate into myeloid progenitors in the bone marrow where, under the influence of growth and colony stimulating factors, the cells differentiate into monoblasts. Monoblasts in turn develop into monocytes and migrate from the bone marrow into the blood where they circulate for several days and then are distributed to the tissues either as resident macrophages or as recruited macrophages at sites of infection and inflammation. Resident macrophages are phenotypically and functionally influenced by their environment, which varies with the anatomical location. During an inflammatory reaction, circulating monocytes adhere and migrate across the endothelium in response to chemoattractant gradients generated by stromal and inflammatory cells. Depending on the extracellular milieu, the cells may become polarized, exhibiting characteristics of M1 and/or M2 macrophages.

PU.1 is particularly important, because it regulates the expression of the receptor for M-CSF, which is critical for M-CSFdependent differentiation. ${ }^{18}$ The transcription factors GATA-2, $\mathrm{SCL}$, and c-Myb regulate myeloid cell survival. Additional transcription factors, including NF-M/C/EBP $\alpha$ HOXB7 and c-Myc regulate the intermediate stages of myeloid differentiation, and C/EBP $\beta$, EBR-1, IRF-1, NF-Y, and some Jun/Fos and Stat proteins regulate monocyte maturation. ${ }^{19,20}$

After leaving the bone marrow, monocytes enter the blood compartment, where they circulate for days before migrating into tissues, ${ }^{21,22}$ including the mucosa (Figure 2). Circulating monocytes are typically CD14 ${ }^{+}$and express Fc receptors, chemokine receptors, adhesion molecules, and TLRs, surface molecules that contribute to cell recruitment, retention, and pathogen-associated molecular pattern recognition at sites of infection and/or inflammation. After migration into the tissue, monocytes enlarge as they increase their content of lysosomal and hydrolytic enzymes, number and size of mitochondria, and energy requirements to become terminally differentiated resident macrophages. Distinct functional roles have been reported for subpopulations of macrophages. Referred to as M1 and M2 macrophages (Figure 2), these populations polarize generally along the Th1/Th2 paradigm based on cytokine release, chemokine elaboration, and enzyme production. ${ }^{23-25}$ Such polarization is not well defined in human mucosal macrophages, ${ }^{26,27}$ and we have not yet detected heterogeneity in macrophages isolated from normal human intestine, despite their functional proximity to M2 populations. After a period of weeks to possibly several months, ${ }^{21,22}$ tissue macrophages undergo programmed cell death and are replaced by newly recruited blood monocytes.

\section{RECRUITMENT OF MONOCYTES TO INFLAMED AND NONINFLAMED GASTROINTESTINAL MUCOSA}

Tissue mononuclear cells are replenished through the proliferation of resident cells, the migration of adjacent tissue cells, and the recruitment of circulating precursor cells. Intestinal macrophages, however, like many differentiated resident myeloid cells, do not proliferate and appear incapable of receptor-mediated chemotactic activity. ${ }^{28}$ Thus, the recruitment of circulating precursor monocytes is the likely source of cells for the replacement of senescent and apoptotic macrophages in the gastrointestinal tract mucosa.

In noninflamed intestinal mucosa, transforming growth factor- $\beta$ (TGF- $\beta$ ) and IL- 8 are constitutively produced by mucosal epithelial cells and mast cells and then bind to and are released by the lamina propria extracellular matrix (stroma). ${ }^{28-30} \mathrm{In}$ response to the potent chemokine activity of TGF- $\beta$ and IL- 8 , circulating blood monocytes localize to the lamina propria to become resident macrophages (Figures 1, 2, and 4). Supporting this concept, we have shown that intestinal stromal TGF- $\beta$ and IL-8 recruit blood monocytes, ${ }^{28}$ an important finding because TGF- $\beta$ is the most potent natural chemokine for monocytes, ${ }^{31,32}$ yet neither TGF- $\beta$ nor IL-8 induce chemotaxis by isolated intestinal macrophages. That chemokines released by the lamina propria extracellular matrix contribute to the recruitment of monocytes to noninflamed lamina propria is consistent with the gastrointestinal tract lamina propria being the largest reservoir of macrophages in the body. Thus, gut macrophages are derived exclusively from recruited blood monocytes, and, after terminal differentiation, they become resident macrophages in the mucosa of the small intestine and 

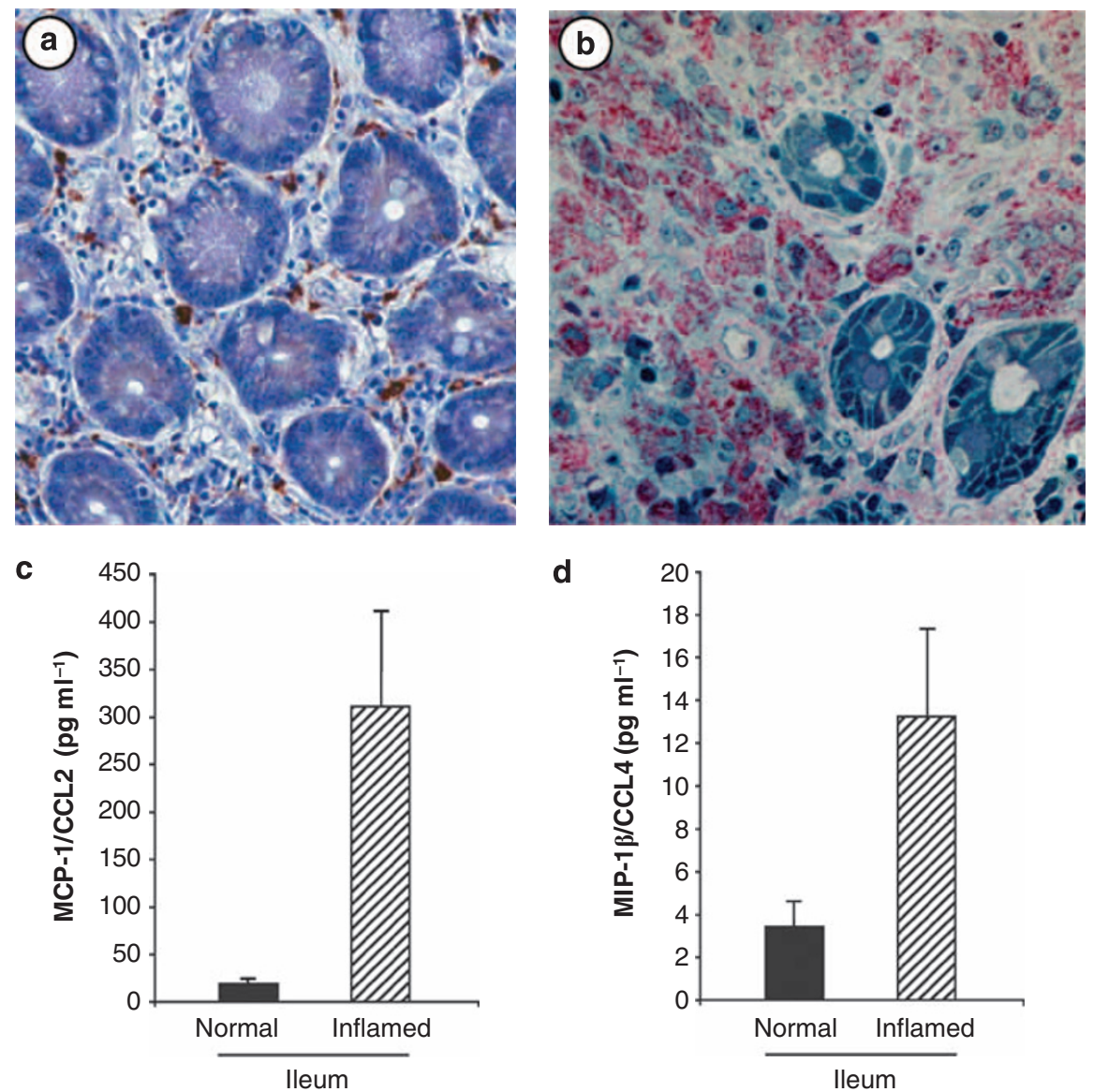

Figure 3 Influx of macrophages into the lamina propria in response to infection or inflammation. (a) Normal intestinal tissue (ileum) in which CD68 ${ }^{+}$ macrophages are distributed throughout the lamina propria. (b) Infection of an immunocompromised individual with $M$. avium (identified by red acid fast stain) results in striking increases in macrophage accumulation and phagocytosis of the bacteria in the lamina propria. (c, d) Conditioned medium obtained from normal/noninflamed intestinal tissues and from inflamed (inflammatory bowel disease (IBD)) tissues (ileum) reveals a significant elevation of monocyte-targeted chemokines including MCP-1/CCL2 (monocyte chemotactic protein-1/chemokine (C-C motif) ligand 2) and MIP-1 $\beta / C C L 4$ (macrophage inflammatory protein-1/chemokine (C-C motif) ligand 4), which contribute to the recruitment of monocytes into inflamed or infected intestinal sites. Chemokine levels were determined using a bead-based multiplex cytokine assay (Biosource International, Camarillo, CA).

colon, where they survive for weeks to months, characteristic of macrophages in other tissues..$^{20,21}$

In studies of macrophage accumulation in inflamed gastrointestinal mucosa, immunohistochemical analysis has shown that the endothelial cells lining small blood vessels in the mucosa of patients with Crohn's disease display high levels of CD34, a ligand that promotes the rolling of $\mathrm{L}$-selectin ${ }^{+}$monocytes in high endothelial venules. ${ }^{33}$ More recently, antibody blocking studies have shown that PSLG-1 (P-selectin glycoprotein ligand-1), P-selectin, and VCAM-1 (vascular cell adhesion molecule-1) promote $\mathrm{CD} 14^{+}$monocyte rolling and adherence in the intestinal mucosa, particularly ileal mucosa, in a mouse model of spontaneous ileitis. ${ }^{34}$ Finally, increased levels of ICAM-1 (intercellular adhesion molecule 1) and CD31, which facilitate transendothelial migration of monocytes, are also present in Crohn's disease lesions. ${ }^{33}$ Thus, endothelial cells in mucosal vessels express molecules that promote the rolling, adherence, and subsequent transendothelial migration of circulating blood monocytes into inflamed gastrointestinal mucosa. In addition, recruitment factors, including CCL2 and CCL4 (chemokine (C-C motif) ligand 2 and 4; Figure 3) that selec- tively induce monocyte transendothelial migration and accumulation, may be released in inflamed and/or infected mucosa, enhancing the migration of monocytes into the mucosa.

In the 1990s, macrophages in normal human colonic and intestinal mucosa were shown to lack CD $14 . .^{35,36}$ In contrast, the expression of this receptor on a substantial proportion of mucosal macrophages in patients with inflammatory bowel disease ${ }^{33,37-39}$ suggested that significant numbers of newly recruited blood monocytes, which express CD14, are present in the inflamed mucosa. The absence of other features, including CD80 expression ${ }^{40}$ and respiratory burst activity, ${ }^{41}$ in macrophages in normal gut mucosa, but the presence of these features in macrophages in the inflamed mucosa of patients with Crohn's disease is consistent with blood monocyte recruitment to sites of mucosal inflammation. To explore experimentally the origin of $\mathrm{CD} 14^{+}$macrophages in inflamed mucosa, Grimm et al. ${ }^{42}$ showed that $\mathrm{CD} 14^{+}$blood monocytes harvested from subjects with inflammatory bowel disease, labeled with ${ }^{99 \mathrm{~m}}$ technetium, and then inoculated back into the respective subjects migrated to the inflamed mucosa, confirming that the CD14 ${ }^{+}$ macrophages in the inflammatory lesions were newly recruited 
proinflammatory blood monocytes. In this regard, the recently described ${ }^{43}$ subset of macrophages isolated from the colon (not small intestine) of patients with inflammatory bowel disease that expressed CD14 and released proinflammatory cytokines likely represents newly recruited blood monocytes.

The recruitment of monocytes to the gastrointestinal mucosa is also accelerated during mucosal infection with organisms such as Mycobacterium avium, as shown in the infected human intestine in Figure 3. Compared with the prevalence of lamina propria macrophages in normal gut mucosa, the number of mucosal macrophages increases in response to bacterial and viral invasion, ${ }^{44,45}$ as demonstrated by the increased number of lamina propria macrophages with internalized mycobacteria in $M$. avium-infected mucosa (Figure 3). Whether mucosal macrophages infected with opportunistic pathogens in immunosuppressed subjects exhibit a $\mathrm{CD} 14^{+}$phenotype has not been defined, but the cells likely represent monocyte-derived macrophages that have exited the circulation at sites of infection and whose proinflammatory cytokine-chemokine profile has been dysregulated by the intracellular pathogen. ${ }^{46,47}$

\section{MUCOSAL MACROPHAGE RECOGNITION OF PATHOGENS}

To distinguish between self and microorganisms, gut macrophages express an array of recognition receptors (Table $\mathbf{1}$ ), including TLRs 3-9, which are often present at higher levels than on autologous blood monocytes. ${ }^{48}$ These receptors recognize conserved pathogen motifs such as lipopolysaccharide (LPS) and lipoteichoic acid on the surface of Gram-negative and Grampositive bacteria, bacterial flagellins, and single-stranded RNA and DNA fragments, allowing the cells to detect infectious agents. Intestinal macrophages, like monocytes and monocyte-derived macrophages, ${ }^{49-52}$ also express receptors for lipoprotein and phospholipid on apoptotic cells (CD36), ${ }^{29}$ formyl C5aR peptides in bacteria (fMLPR), and complement component $5 \mathrm{a}(\mathrm{C} 5 \mathrm{aR}){ }^{28}$ The presence of these innate receptors on intestinal macrophages facilitates the cells' efficient chemotaxis to and phagocytosis of bacteria, including Escherichia coli and Salmonella, and fungi such as the yeast Candida albicans. ${ }^{29,36}$ The ability of intestinal macrophages to phagocytose inert material ${ }^{29,53}$ and apoptotic mononuclear cells (L.E. Smythies, unpublished) is critical for the clearance of pathogen/cell debris and dead cells in the mucosal lamina propria. Intriguingly, intestinal macrophages lack the receptors for IgA and $\operatorname{IgG}^{29,53}$ (Table 1), which mediate the recognition and uptake of IgA- and IgG-opsonized cells or particles, reducing mucosal macrophage integration of innate and adaptive immune responses. Thus, although resident intestinal macrophages lack some innate receptors, for example, Ig receptors and the LPS co-receptor (CD14) discussed below, they express receptors for conserved structures on bacteria, viruses, yeast, and certain parasites, which promote recognition of potentially harmful microbes and their subsequent phagocytosis.

Mutations in innate response genes that mediate bacterial recognition and processing have been identified as susceptibility loci for Crohn's disease. The first such gene to be identified was NOD2/CARD15 (nucleotide-binding oligomerization domain $2 /$ caspase activation and recruitment domain 15), ${ }^{54,55}$ which
Table 1 Phenotypic and functional differences between monocytes, macrophages, and intestinal macrophages

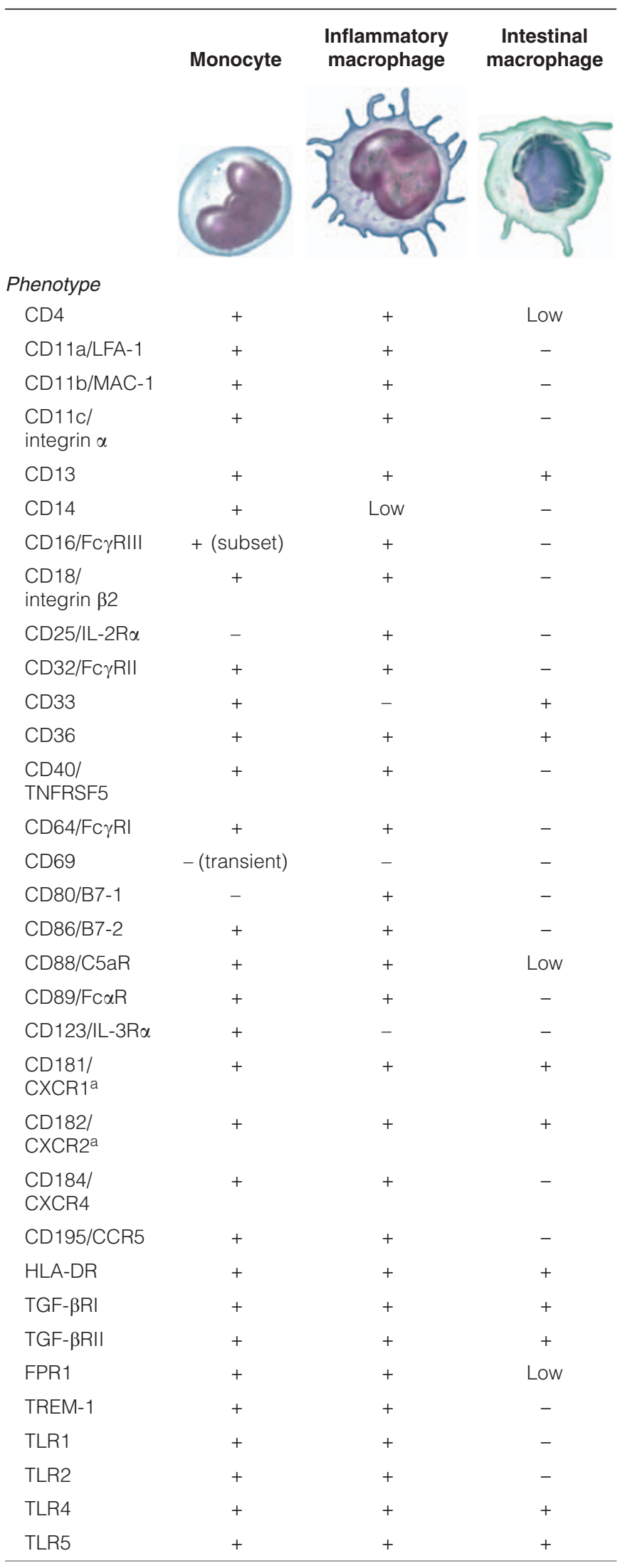

Table 1 continued on the following page 
Table 1 (Continued)

\begin{tabular}{|c|c|c|c|}
\hline & Monocyte & $\begin{array}{c}\text { Inflammatory } \\
\text { macrophage }\end{array}$ & $\begin{array}{c}\text { Intestinal } \\
\text { macrophage }\end{array}$ \\
\hline TLR6 & + & + & + \\
\hline TLR10 & + & + & $?$ \\
\hline TLR11 & + & + & $?$ \\
\hline \multicolumn{4}{|l|}{ Function } \\
\hline Phagocytosis & + & + & + \\
\hline Killing & + & + & + \\
\hline Chemotaxis & + & $+1-$ & - \\
\hline $\begin{array}{l}\text { Respiratory } \\
\text { burst }\end{array}$ & + & + & - \\
\hline $\begin{array}{l}\mathrm{Ag} \\
\text { presentation }\end{array}$ & + & + & $?$ \\
\hline $\begin{array}{l}\text { Cytokine } \\
\text { production }\end{array}$ & + & + & - \\
\hline Costimulation & + & + & - \\
\hline
\end{tabular}

Abbreviations: C5aR, complement component 5a receptor; CCR5, C-C chemokine receptor type 5; CXCR, chemokine (C-X-C motif) receptor; FPR1, formyl peptide receptor $1 ; \mathrm{IL}-2 \mathrm{R}$, interleukin-2 receptor; LFA-1, Iymphocyte function-associated antigen 1; MAC-1, macrophage-1 antigen; TGF- $\beta$, transforming growth factor- $\beta$; TLR, Toll-like receptor; TNFRSF5, tumor necrosis factor receptor superfamily, member 5; TREM-1, triggering receptor expression on myeloid cells 1; ?, not known. ${ }^{\mathrm{a} C D} 181 / \mathrm{CXCR} 1=\mathrm{IL}-8 \mathrm{R} \alpha ; \mathrm{CD} 182 / \mathrm{CXCR} 2=\mathrm{IL}-8 \mathrm{R} \beta$

encodes intracellular pattern recognition receptors for muramyl dipeptide, a component of the peptidoglycan cell wall in Grampositive and Gram-negative bacteria. Mutations in the ATG16L1 (autophagy-related like 1) ${ }^{56,57}$ and IRGM (immunity-related GTPase family M $)^{58,59}$ genes, which encode proteins involved in autophagy, a process by which cell debris is directed into double-membrane autophagosomes for delivery into the lysosomal degradation pathway and by which intracellular bacterial growth is inhibited, have also been identified as genetic risk factors for Crohn's disease. These sets of genes appear functionally linked, as NOD1 and NOD2 were recently shown to recruit the autophagy protein ATG16L1 to the plasma membrane at the bacterial entry site to facilitate autophagosome formation. ${ }^{60}$ NOD2 has been shown to mediate intracellular recognition of Streptococcus pneumoniae, S. Typhimurium, Mycobacterium spp., and Listeria monocytogenes, and potentially some viruses in experiments utilizing cell lines and murine models. ${ }^{61-63}$ Also, Gram-negative and Gram-positive bacteria have been shown to induce monocyte-derived DCs via NOD2 recognition in order to polarize $\mathrm{CD} 4{ }^{+} \mathrm{T}$ cells for the production of IL-17, ${ }^{64} \mathrm{a}$ cytokine that is associated with the inflammatory response in Crohn's disease. ${ }^{65-68}$

Complementing the NOD2 studies, model systems have been used to show a crucial role for the ATG16L1 gene product in intracellular clearance of $M$. tuberculosis, S. Typhimurium, and Streptococcus pyogenes. ${ }^{61}$ Importantly, intracellular replication of adherent-invasive E. coli, which colonize the intestinal mucosa in high numbers in patients with Crohn's disease, ${ }^{69,70}$ is inhibited by normal autophagy but enhanced in epithelial cell lines with defective autophagy. ${ }^{71}$ As many of the bacteria used to study autophagy in these models infect and replicate in macro- phages, it will be important to determine the role of autophagy in intestinal macrophage clearance of the organisms, particularly adherent-invasive E. coli. Genome-wide association studies will likely identify other genes that regulate intracellular pathogen recognition and clearance in mucosal macrophages.

The host response to gut microbes can have broad negative consequences, reflected in recent evidence linking the mucosal response to enteric bacteria and the development of autoimmune diseases. ${ }^{72}$ For example, mice engineered to develop arthritis exhibit delayed and less severe arthritis in germ-free conditions, but the inoculation of a single enteric bacteria induces arthritis via Th17 cell activity. ${ }^{73}$ Murine intestinal and colonic macrophages express IL-10, which together with retinoic acid and TGF- $\beta$ induce the differentiation of forkhead box $3^{+}\left(\right.$Foxp $\left.^{+}\right)$regulatory $\mathrm{T}$ (Treg) cells, promoting a tolerogenic mucosal microenvironment, ${ }^{74}$ but human intestinal macrophages do not appear to produce detectable IL-10 or other immunoregulatory cytokines. ${ }^{29,48}$ Polarization of CD $4^{+}$ T helper lymphocytes into cells of the Th17 lineage represents a response to intestinal microbe colonization, in the context of Th17-lineage promoting TGF- $\beta{ }^{75}$ Additional local promoters of Th17 accumulation include IL-23 and IL-6, provided, in part, by recruited $\mathrm{CD} 14^{+}$intestinal macrophages. ${ }^{43,76}$ In turn, local Th17 populations may become enabling for distal autoimmune lesions, characterized by accumulation and generation of IL-17 and related factors. ${ }^{77}$ Consequently, failure to regulate myeloid cell activation and responses to gut microbiota may precipitate or contribute to the development of intestinal and extraintestinal autoimmune inflammatory diseases.

\section{MUCOSAL MACROPHAGE PHAGOCYTOSIS AND KILLING OF PATHOGENS}

Receptor-mediated recognition is the first step in the interaction between mucosal macrophages and microorganisms. Consistent with their central role in host defense against microbes and noxious molecules that have reached the epithelium, recognition initiates engulfment, which leads to killing and degradation of the microbe. Intestinal macrophages exhibit greater phagocytic activity for inert material and stronger bacteriocidal activity than autologous blood monocytes. ${ }^{29}$ However, intestinal macrophage phagocytosis does not induce cytokine release, irrespective of the internalized object, whereas monocyte phagocytosis of either inert material or bacteria results in strong proinflammatory cytokine release. Thus, in contrast to blood monocytes and macrophages in other tissues, resident intestinal macrophages perform host defense activities without inducing an inflammatory response, thereby contributing to the absence of inflammation during microbe encroachment. The mechanisms by which intestinal macrophages kill bacteria are not known, but the cells' bactericidal activity appears to be independent of reactive oxygen intermediates $^{41}$ (P.D. Smith, unpublished observations).

In immunocompromised conditions, newly recruited monocytes and resident macrophages avidly phagocytose certain pathogens, particularly opportunistic microorganisms such as M. avium, but internalization may not lead to degradation of the organism (Figure 3). ${ }^{45}$ The mechanisms responsible for defective 
macrophage clearance of such organisms are not known, but deficits in $\mathrm{CD} 4^{+} \mathrm{T}$ cells and interferon- $\gamma$ triggering are likely contributing factors. ${ }^{45,46}$ Besides M. avium, tissue macrophages, including mucosal macrophages, are capable of harboring other intracellular pathogens such as M. tuberculosis, Histoplasma capsulatum, and cytomegalovirus. ${ }^{78,79}$

\section{MECHANISMS THAT DAMPEN RESIDENT MUCOSAL MACROPHAGE INFLAMMATORY RESPONSES}

For millions of years, an astonishingly unhygienic external environment presented the evolving intestine of early vertebrates, then non-human primates, and eventually humans, a spectrum of colonized microorganisms and infectious pathogens likely far greater in complexity and numbers than the "typical" enteric microbiota of today. In such an inhospitable environment, a disrupted intestinal epithelium resulting from frequent infections was probably common. Because the exposure of myeloid effector cells to mucosal bacteria or their products can trigger a striking, and potentially life-threatening, proinflammatory transcriptional response, ${ }^{49}$ the gastrointestinal mucosa co-evolved to downregulate inflammatory, but not antimicrobial, responses to lumenal microorganisms that breach the disrupted epithelium. During this co-evolution, resident lamina propria macrophages emerged, at least in humans, unique for their capacity to phagocytose and digest microorganisms and innate material without an inflammatory response, a distinct selective advantage to the host. Extended to immune surveillance, our unpublished findings indicate that intestinal macrophages also scavenge apoptotic mononuclear cells without the release of proinflammatory cytokines. Today, the unique phenotype and functional profile of gut macrophages described below likely contributes to the absence of mucosal inflammation in the small intestine, despite a "cleaner" microbiota.

The ability of macrophages to elaborate over 100 secretory products contributes to the cells' ability to perform proinflammatory, host defense, and tissue remodeling activities. ${ }^{49,80}$ To reconcile this exuberant inflammatory potential and the absence of inflammation in the normal human small intestine, we have shown that intestinal macrophages are potently downregulated at both mRNA and protein levels for multiple innate response molecules (Table 1), including the receptors for LPS (CD14), Fc $\alpha$ (CD89), Fc $\gamma$ (CD64, CD32, CD16), CR3 (CD11b/CD18), and CR4 (CD11c/CD18); receptors for the growth factors IL-2 (CD25) and IL-3 (CD123); and the integrin LFA-1 (CD11a/CD18), the costimulatory molecules CD40, CD80, and CD86, and TREM-1 (triggering receptor expression on myeloid cells 1). ${ }^{29,36,48,53,81}$ Intestinal macrophages are also downregulated for the production of TLR-inducible cytokines, including proinflammatory IL-1, IL-6, IL-8, tumor necrosis factor- $\alpha$, IL-10, and RANTES, irrespective of the stimulus (bacterial products, cytokines, and phagocytosis). ${ }^{29,53}$ The inability of most intestinal macrophages to elaborate proinflammatory cytokines is the consequence of near-absent or markedly reduced MyD88 (myeloid differentiation primary response gene (88)), Toll/IL-1 receptor (TIR)-domain containing adapter-inducing IFN $\beta$ adapter protein, and TRAF6 (tumor necrosis factor receptor-associated factor 6) signal protein. ${ }^{48}$ As MyD88 is crucial for nuclear factor (NF) $-\kappa B$ activation of all TLRs except TLR3, and as TIR mediates TLR3-induced RANTES and interferon- $\beta$ production (as well as TLR4-mediated MyD88-independent signaling), the downregulated MyD88 and TIR predictably result in NF- $\kappa \mathrm{B}$ inactivation. Moreover, as TREM-1 appears inducible by TLR2/4 ligands and requires TIR to signal an LPS response, ${ }^{82}$ the compromised TLR signaling and downregulated TIR expression likely contribute to reduced TREM-1 responsiveness in intestinal macrophages. ${ }^{83-86}$ In addition, active Smad signaling in the macrophages promotes constitutive expression of I $B \alpha$, the negative regulator of $\mathrm{NF}-\kappa \mathrm{B}$, which together with the cells' inability to phosphorylate NF- $\kappa B$ and I $\kappa B \alpha$, also blocks the cells' ability to propagate an NF- $\kappa B$ signal, leading to inhibition of NF- $\kappa B$-mediated activities and profound inflammation anergy. Consistent with these findings, TGF- $\beta$ has also been shown to block NF- $\kappa B$ activation in response to TLR2, 4 , and 5 signaling by facilitating ubiquitination and proteosomal degradation of MyD88.${ }^{87}$ Remarkably, extracellular matrix (stroma) TGF- $\beta$ induces similar downregulation in NF- $\mathrm{KB}$ signaling and NF$\kappa \mathrm{B}$-mediated function in blood monocytes, ${ }^{48}$ implicating stromal TGF- $\beta$ in the inactivation of NF- $\kappa \mathrm{B}$ that characterizes the differentiation of proinflammatory blood monocytes into noninflammatory intestinal macrophages. Importantly, in the mucosa of people with inflammatory bowel disease, intestinal macrophages may express high levels of NF- $\kappa \mathrm{B}$ DNA-binding activity, ${ }^{88}$ and NF- $\mathrm{\kappa B}$ may be activated; ${ }^{89}$ these cells likely represent newly recruited monocytes that have not been downregulated because of the loss of normal homeostatic controls.

In the mucosa, latent TGF- $\beta$ is produced by an array of different cells, including epithelial cells, mast cells, and stromal cells (Figures 1 and 4). Under homeostatic conditions, T cells undergoing apoptosis are not only a target for phagocytic cells but also release TGF- $\beta$ from their intracellular membrane-bound compartment ${ }^{90}$ and thus constitute another important source of TGF- $\beta$ in the mucosal lamina propria (Figures 1 and 4 ). This protective response facilitates noninflammatory clearance of dead cells, as well as the noninflammatory engulfment and clearance of invading intestinal microorganisms by resident macrophages. In the setting of inflammation, the recognition and uptake of apoptotic mucosal cells by newly recruited monocytes provides another source of immunoregulatory cytokines, including TGF- $\beta .{ }^{91,92}$ The subsequent binding of the TGF- $\beta$ to lamina propria extracellular matrix (stroma) via extracellular binding domains (Figure 4b) establishes a "TGF- $\beta$ reservoir."30,32,93 Activation and release of TGF- $\beta$ from the reservoir leads to engagement of cognate receptors TGF- $\beta \mathrm{R} 1$ and TGF- $\beta \mathrm{R} 2$ expressed on intestinal macrophages, ${ }^{28}$ and newly recruited monocytes (Figure 4d), promoting cell recruitment, noninflammatory host defense, and noninflammatory immune surveillance of apoptotic cells.

Another influence on macrophage behavior is the population of Foxp $3^{+}$Treg cells. In addition to thymus-derived Tregs, 

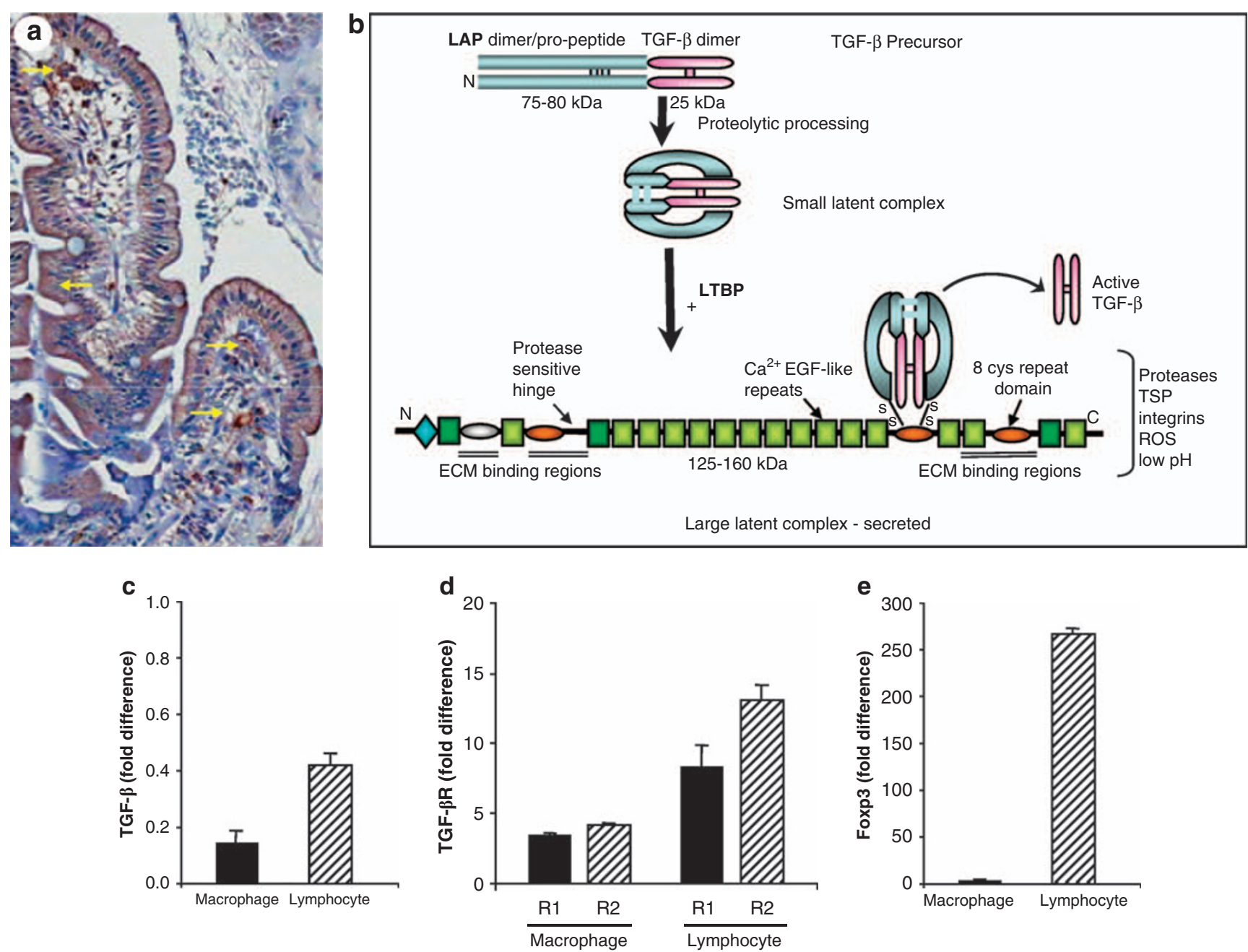

Figure 4 Constitutive and inducible expression of transforming growth factor- $\beta$ (TGF- $\beta$ ). (a) Section of intestinal mucosa shows TGF- $\beta$ staining in epithelial cells (arrows) and cells morphologically consistent with lymphocytes, and mast cells (arrows), and the lamina propria matrix. (b) TGF- $\beta$ is secreted as a large latent complex that contains extracellular matrix (ECM) binding domains and is retained in a latent state while attached to ECM. Once TGF- $\beta$ is activated and released from the ECM, it can interact with TGF- $\beta$ receptors on target cells to initiate Smad-dependent and -independent signaling (adapted from ref. 133). (c-e) Lymphocytes and macrophages were isolated from noninflamed intestinal mucosa and RNA prepared for reverse transcriptase PCR (RT-PCR) for (c) TGF- $\beta$, (d) TGF- $\beta$ R1 and TGF- $\beta$ R2, and (e) forkhead box p3 (Foxp3). Results were obtained using the $2^{-\Delta \Delta C t}$ method and expressed as fold difference relative to isolated peripheral blood monocyte populations.

peripheral $\mathrm{CD} 4{ }^{+} \mathrm{T}$ cells, under the influence of antigen-specific receptor stimulation in the presence of TGF- $\beta$, are induced to express the transcription factor Foxp3 and orchestrate suppression of both pathologic and healthy immune responses. ${ }^{94-96}$ In support of these tolerogenic pathways, lymphocytes isolated from the lamina propria represent an abundant source of Foxp3 expression (Figure 4e), consistent with their important role in providing additional protection from the untoward consequences of an unrestricted inflammatory response to the intestinal microbiota. Indeed, the prevalence of these important immunoregulatory cells is increased in the lamina propria of the intestine in people with Crohn's disease ${ }^{97}$ and the stomach in children with Helicobacter pylori infection. ${ }^{98}$

Peripheral tolerance to nonpathogenic microbes and/or environmental antigens is also coordinated via intestinal lamina propria DCs that require activation of the $\beta$-catenin signaling pathway to secrete immunosuppressive cytokines that drive
Treg cell induction. ${ }^{99}$ Intimately linked to intestinal homeostasis, altered expression of TGF- $\beta$ and/or expression of other coregulatory cytokines (i.e., IL-6, IL-1, and IL-10) sets in motion a cascade of immunopathogenic events. As failure to limit innate pathways is linked to the development of intestinal disease, multiple non-redundant pathways are in place to control these events. Continued elucidation of these complex pathways will enhance our understanding of how innate responses protect the host from commensal and pathogenic microbes, providing rationale for the design of new approaches to intervention, with an emphasis on intestinal macrophages and their return to homeostasis and regenerative functions.

\section{MUCOSAL MACROPHAGES AND DEFENSE AGAINST HIV-1}

The mucosal surfaces of the gastrointestinal tract are the route by which human immunodeficiency virus-1 (HIV-1) enters the host in most mother-to-child and male homosexual transmissions. 
Routes of entry into the lamina propria include direct inoculation through an epithelium disrupted by trauma or infection, uptake by intraepithelial DC processes, M-cell translocation, and epithelial cell transcytosis ${ }^{100-103}$ (Figure 1). In the lamina propria, HIV-1 encounters permissive intestinal $\mathrm{CD} 4^{+} \mathrm{CCR} 5^{+}$ $\mathrm{T}$ cells, ${ }^{104}$ which support productive viral infection and undergo early, rapid, and profound depletion during primary HIV-1 and simian immunodeficiency virus infection. ${ }^{105-112}$ Resident macrophages in the human small intestine, however, are incapable of supporting productive HIV-1 infection, ${ }^{113-115}$ although extraintestinal macrophages have crucial roles in the establishment, pathogenesis, and latency of HIV-1 infection. ${ }^{116-123}$ The nonpermissiveness of intestinal macrophages to HIV-1 appears to be the consequence of marked downregulation of surface CD4/CCR5 expression and NF- $\kappa B$ activation (R. Shen, unpublished data), requirements for HIV-1 entry and transcription, respectively. However, after $\mathrm{CD} 4{ }^{+} \mathrm{T}$-cell depletion in late-stage disease, HIV-1-infected monocytes circulating in the blood may be recruited to inflamed mucosa deficient in normal downregulatory mechanisms, allowing viral replication to continue after the cells take up residence in the lamina propria, as we have reported for esophageal macrophages in patients with AIDS and opportunistic mucosal infections. ${ }^{124}$ Indeed, tissue macrophages infected with opportunistic pathogens are particularly vulnerable to productive infection and can represent formidable cellular factories of HIV-1 production. ${ }^{45,119}$

Differential expression of host cell antiviral mechanisms in monocytes compared with mature macrophages contribute to their discordant HIV-1 permissiveness. ${ }^{125-128}$ Such restrictions include cytoplasmic APOBEC (apolipoprotein B mRNA-editing enzyme catalytic polypeptide-like) subunits, particularly APOBEC3G (hA3G) and hA3A, ${ }^{129,130}$ which become incorporated into virions and cause $\mathrm{dC}$-to-dU mutations in nascent HIV-1 DNA during reverse transcription and lead to subsequent viral degradation. ${ }^{130-132}$ However, resident intestinal macrophages appear to have a post-entry block in the capacity to replicate virus ${ }^{115}$ not readily attributable to APOBEC (R. Shen, unpublished data). Elucidation of the mechanisms responsible for the inability of intestinal macrophages to support HIV-1 infection are currently receiving intense investigative attention in an attempt to inform development of novel therapeutic strategies based on endogenous restriction.

\section{CONCLUDING REMARKS}

Monocytes exit the circulation and take up residence in tissues throughout the body. Of these populations, lamina propria macrophages in the distinct microenvironment of the gastrointestinal mucosa acquire a unique phenotypic and functional profile, mediated at least in part by matrix-bound TGF- $\beta$ and Treg cells. In the homeostatic conditions of noninflamed mucosa, many pattern recognition receptors are downregulated, along with their pathogen-associated molecular pattern-engaged signal transduction pathways, resulting in inflammation anergy. In the event of an epithelial breach and/or microbial invasion, however, the suppressive milieu is challenged by newly recruited circulating monocytes and lymphocytes, which generate proinflammatory mediators and engage a protective response. Failure to resolve this antimicrobial response and return the mucosa to steadystate conditions can promote chronic inflammation in an array of mucosal diseases.

\section{ACKNOWLEDGMENTS}

We are grateful to Calley Grace for editorial assistance and Dr J. Orenstein for tissue biopsies. This work was supported by the National Institutes of Health (DK-47322, DK-54495, Al-83027, Al-83539, DK-84063, Al-74438, and RR-20136), the University of Alabama at Birmingham Mucosal HIV and Immunobiology Center (DK-64400), the Crohn's and Colitis Foundation of America, the Research Service of the Veterans Administration, and the Intramural Research Program of the National Institutes of Health, National Institute of Dental and Craniofacial Research, Bethesda, MD.

\section{DISCLOSURE}

The authors declared no conflict of interest.

(C) 2011 Society for Mucosal Immunology

\section{REFERENCES}

1. Lee, S.H., Starkey, P.M. \& Gordon, S. Quantitative analysis of total macrophage content in adult mouse tissues: immunochemical studies with monoclonal antibody F4/80. J. Exp. Med. 161, 475-489 (1985).

2. Smith, P.D., Smythies, L.E. \& Wahl, S.M. Macrophage effector function In Clinical Immunology. Vol 1 (Rich, R.R., Fleisher, T.A., Sherarer, W.T., Kotzin, B. \& Schroeder, H.W.J., eds) 19.11-19.19 (Harcourt Health Sciences, London, 2001).

3. Hoffman, J.A., Kafatos, F.C., Janeway, C.A. Jr \& Ezekowitz, R.A.B. Phylogenetic perspectives in innate immunity. Science 284, 1313-1318 (1999).

4. Round, J.L. \& Mazmanian, S.K. The gut microbiota shapes intestinal immune responses during health and disease. Nat. Rev. Immunol. 9, 313-323 (2009).

5. Malamud, D. \& Wahl, S.M. The mouth: a gateway or a trap for HIV? AIDS 24, 5-16 (2010).

6. Ma, G. et al. Secretory leukocyte protease inhibitor binds to annexin II, a cofactor for macrophage HIV-1 infection. J. Exp. Med. 200, 1337-1346 (2004).

7. Fukata, M., Vamadevan, A.S. \& Abreu, M.T. Toll-like receptors (TLRs) and Nod-like receptors (NLRs) in inflammatory disorders. Semin. Immunol. 21, 242-253 (2009).

8. Bortoluci, K.R. \& Medzhitov, R. Control of infection by pyroptosis and autophagy: role of TLR and NLR. Cell. Mol. Life Sci. 67, 1643-1651 (2010).

9. Miao, E.A. et al. Innate immune detection of the type III secretion apparatus through the NLRC4 inflammasome. Proc. Natl. Acad. Sci. USA 107, 3076-3080 (2010).

10. Guo, P. et al. Dual nature of the adaptive immune system in lampreys. Nature 459, 796-801 (2009).

11. Fearon, D.T. \& Locksley, R.M. The instructive role of innate immunity in the acquired immune response. Science 272, 50-54 (1996).

12. Roach, J.C. et al. The evolution of vertebrate Toll-like receptors. Proc. Natl. Acad. Sci. USA 102, 9577-9582 (2005).

13. Gordon, S., Clarke, S., Greaves, D. \& Doyle, A. Molecular immunobiology of macrophages: recent progress. Curr. Opin. Immunol. 7, 24-33 (1995).

14. Valledor, A.F., Borras, F.E., Cullell-Young, M. \& Celada, A. Transcription factors that regulate monocyte/macrophage differentiation. J. Leukoc. Biol. 63, 405-417 (1998).

15. Fogg, D.K. et al. A clonogenic bone marrow progenitor specific for macrophages and dendritic cells. Science 311, 83-87 (2006).

16. McKercher, S.R. et al. Targeted disruption of the PU.1 gene results in multiple hematopoietic abnormalities. EMBO J. 15, 5647-5658 (1996).

17. Nagamura-Inoue, T., Tamura, T. \& Ozato, K. Transcription factors that regulate growth and differentiation of myeloid cells. Int. Rev. Immunol. 20, 83-105 (2001).

18. Voso, M.T. et al. Inhibition of hematopoiesis by competitive binding of transcription factor PU.1. Proc. Natl. Acad. Sci. USA 91, 7932-7936 (1994). 
19. Jack, G.D., Zhang, L. \& Friedman, A.D. M-CSF elevates c-Fos and phospho-C/EBPalpha(S21) via ERK whereas G-CSF stimulates SHP2 phosphorylation in marrow progenitors to contribute to myeloid lineage specification. Blood 114, 2172-2180 (2009).

20. Friedman, A.D. Transcriptional control of granulocyte and monocyte development. Oncogene 26, 6816-6828 (2007).

21. Dale, D.C., Boxer, L. \& Liles, W.C. The phagocytes: neutrophils and monocytes. Blood 112, 935-945 (2008).

22. Rees, A.J. Monocyte and macrophage biology: an overview. Semin. Nephrol. 30, 216-233 (2010).

23. Gordon, S. \& Martinez, F.O. Alternative activation of macrophages: mechanism and functions. Immunity 32, 593-604 (2010).

24. Mosser, D.M. \& Edwards, J.P. Exploring the full spectrum of macrophage activation. Nat. Rev. Immunol. 8, 958-969 (2008).

25. Danese, S. \& Mantovani, A. Inflammatory bowel disease and intestinal cancer: a paradigm of the Yin-Yang interplay between inflammation and cancer. Oncogene 29, 3313-3323 (2010).

26. Wendelsdorf, K., Bassaganya-Riera, J., Hontecillas, R. \& Eubank, S. Model of colonic inflammation: immune modulatory mechanisms in inflammatory bowel disease. J. Theor. Biol. 264, 1225-1239 (2010).

27. Moos, V. et al. Impaired immune functions of monocytes and macrophages in Whipple's disease. Gastroenterology 138, 210-220 (2010).

28. Smythies, L.E. et al. Mucosal IL-8 and TGF- $\beta$ recruit blood monocytes: evidence for cross-talk between the lamina propria stroma and myeloid cells. J. Leukoc. Biol. 80, 492-499 (2006).

29. Smythies, L.E. et al. Human intestinal macrophages display profound inflammatory anergy despite avid phagocytic and bacteriocidal activity. J. Clin. Invest. 115, 66-75 (2005).

30. Blobe, G.C., Schiemann, W.P. \& Lodish, H.F. Role of transforming growth factor $\beta$ in human disease. N. Engl. J. Med. 342, 1350-1358 (2000).

31. Wahl, S.M., Hunt, D.A. \& Wakefield, L.M. Transforming growth factor type $\beta$ (TGF- $\beta$ ) induces monocyte chemotaxis and growth factor production. Proc. Natl. Acad. Sci. USA 84, 5788-5792 (1987).

32. Wahl, S.M. Transforming growth factor-beta: innately bipolar. Curr. Opin. Immunol. 19, 55-62 (2007).

33. Burgio, V.T., Fais, S., Boirivant, M., Perrone, A. \& Pallone, F. Peripheral monocyte and naive T-cell recruitment and activation in Crohn's disease. Gastroenterology 109, 1029-1038 (1995).

34. Inoue, T. et al. Blockade of PSGL-1 attenuates CD14+ monocytic cell recruitment in intestinal mucosa and ameliorates ileitis in SAMP1/Yit mice. J. Leukoc. Biol. 77, 287-295 (2005).

35. Grimm, M.C., Pavli, P. \& Doe, W.F. Evidence for a CD14+ population of monocytes in inflammatory bowel disease mucosa-implications for pathogenesis. Clin. Exp. Immunol. 100, 291-297 (1995).

36. Smith, P.D. et al. Isolation and purification of CD14-negative mucosal macrophages from normal human small intestine. J. Immunol. Methods 202, 1-11 (1997).

37. Allison, M.C. \& Poulter, L.W. Changes in phenotypically distinct mucosal macrophage populations may be a prerequisite for the development of inflammatory bowel disease. Clin. Exp. Immunol. 85, 504-509 (1991).

38. Rugtveit, J., Brandtzaeg, P., Halstensen, T.S., Fausa, O. \& Scott, H. Increased macrophage subset in inflammatory bowel disease: apparent recruitment from peripheral blood monocytes. Gut 35, 669-674 (1994).

39. Mahida, Y.R., Patel, S., Gionchetti, P., Vaux, D. \& Jewell, D.P. Macrophage subpopulations in lamina propria of normal and inflamed colon and terminal ileum. Gut 30, 826-834 (1989).

40. Rugtveit, J., Bakka, A. \& Brandtzaeg, P. Differential distribution of B7.1 (CD80) and B7.2 (CD86) costimulatory molecules on mucosal macrophage subsets in human inflammatory bowel disease (IBD). Clin. Exp. Immunol. 110, 104-113 (1997).

41. Rugtveit, J. et al. Respiratory burst of intestinal macrophages in inflammatory bowel disease is mainly caused by $C D 14^{+} L 1^{+}$monocyte derived cells. Gut 37, 367-373 (1995).

42. Grimm, M.C. et al. Direct evidence of monocyte recruitment to inflammatory bowel disease mucosa. J. Gastroenterol. Hepatol. 10, 387-395 (1995).

43. Kamada, N. et al. Unique CD14 intestinal macrophages contribute to the pathogenesis of Crohn disease via IL-23/IFN-gamma axis. J. Clin. Invest. 118, 2269-2280 (2008).

44. Hale-Donze, H. et al. Mycobacterium avium complex promotes recruitment of monocyte hosts for HIV-1 and bacteria. J. Immunol. 169, 3854-3862 (2002).
45. Orenstein, J.M., Fox, C. \& Wahl, S.M. Macrophages as a source of HIV during opportunistic infections. Science 276, 1857-1861 (1997).

46. Vazquez, N., Greenwell-Wild, T., Rekka, S., Orenstein, J.M. \& Wahl, S.M. Mycobacterium avium-induced SOCS contributes to resistance to IFN-gamma-mediated mycobactericidal activity in human macrophages. J. Leukoc. Biol. 80, 1136-1144 (2006).

47. Greenwell-Wild, T. et al. Mycobacterium avium infection and modulation of human macrophage gene expression. J. Immunol. 169, 6286-6297 (2002).

48. Smythies, L.E. et al. Inflammation anergy in human intestinal macrophages is due to Smad-induced $\mathrm{I}_{\kappa} \mathrm{B} \alpha$ expression and NF- $\mathrm{KB}$ inactivation. J. Biol. Chem. 285, 19593-19604 (2010).

49. Nares, S. et al. Rapid myeloid cell transcriptional and proteomic responses to periodontopathogenic Porphyromonas gingivalis. Am. J. Pathol. 174, 1400-1414 (2009).

50. Areschoug, T. \& Gordon, S. Scavenger receptors: role in innate immunity and microbial pathogenesis. Cell Microbiol. 11, 1160-1169 (2009).

51. Schiffmann, E., Corcoran, B.A. \& Wahl, S.M. N-formylmethionyl peptides as chemoattractants for leucocytes. Proc. Natl. Acad. Sci. USA 72, 1059-1062 (1975).

52. Smith, P.D. et al. Monocyte function in the acquired immune deficiency syndrome. Defective chemotaxis. J. Clin. Invest. 74, 2121-2128 (1984).

53. Smith, P.D. et al. Intestinal macrophages lack CD14 and CD89 and consequently are down-regulated for LPS- and IgA-mediated activities. J. Immunol. 167, 2651-2656 (2001).

54. Hugot, J.P. et al. Association of NOD2 leucine-rich repeat variants with susceptibility to Crohn's disease. Nature 411, 599-603 (2001).

55. Ogura, Y. et al. A frameshift mutation in NOD2 associated with susceptibility to Crohn's disease. Nature 411, 603-606 (2001).

56. Hampe, J. et al. A genome-wide association scan of nonsynonymous SNPs identifies a susceptibility variant for Crohn disease in ATG16L1. Nat. Genet. 39, 207-211 (2007).

57. Rioux, J.D. et al. Genome-wide association study identifies new susceptibility loci for Crohn disease and implicates autophagy in disease pathogenesis. Nat. Genet. 39, 596-604 (2007).

58. Parkes, M. et al. Sequence variants in the autophagy gene IRGM and multiple other replicating loci contribute to Crohn's disease susceptibility. Nat. Genet. 39, 830-832 (2007).

59. Consortium, W.T.C.C. Genome-wide association study of 14,000 cases of seven common diseases and 3,000 shared controls. Nature 447, 661-678 (2007).

60. Travassos, L.H. et al. Nod1 and Nod2 direct autophagy by recruiting ATG16L1 to the plasma membrane at the site of bacterial entry. Nat. Immunol. 11, 55-62 (2010).

61. Glasser, A.L. \& Darfeuille-Michaud, A. Abnormalities in the handling of intracellular bacteria in Crohn's disease: a link between infectious etiology and host genetic susceptibility. Arch. Immunol. Ther. Exp. (Warsz) 56, 237-244 (2008).

62. Cadwell, K., Stappenbeck, T.S. \& Virgin, H.W. Role of autophagy and autophagy genes in inflammatory bowel disease. Curr. Top. Microbiol. Immunol. 335, 141-167 (2009).

63. Cadwell, K. et al. Virus-plus-susceptibility gene interaction determines Crohn's disease gene Atg16L1 phenotypes in intestine. Cell 141, 1135-1145 (2010).

64. van Beelen, A.J. et al. Stimulation of the intracellular bacterial sensor NOD2 programs dendritic cells to promote interleukin-17 production in human memory T cells. Immunity 27, 660-669 (2007).

65. Fujino, S. et al. Increased expression of interleukin 17 in inflammatory bowel disease. Gut 52, 65-70 (2003).

66. Holtta, V. et al. IL-23/IL-17 immunity as a hallmark of Crohn's disease. Inflamm. Bowel. Dis. 14, 1175-1184 (2008).

67. Seiderer, J. et al. Role of the novel Th17 cytokine IL-17F in inflammatory bowel disease (IBD): upregulated colonic IL-17F expression in active Crohn's disease and analysis of the IL17F p.His161Arg polymorphism in IBD. Inflamm. Bowel. Dis. 14, 437-445 (2008).

68. McGovern, D.P. et al. Genetic epistasis of IL23/IL17 pathway genes in Crohn's disease. Inflamm. Bowel. Dis. 15, 883-889 (2009).

69. Darfeuille-Michaud, A. et al. Presence of adherent Escherichia coli strains in ileal mucosa of patients with Crohn's disease. Gastroenterology 115, 1405-1413 (1998).

70. Martin, H.M. et al. Enhanced Escherichia coli adherence and invasion in Crohn's disease and colon cancer. Gastroenterology 127, 80-93 (2004). 
71. Lapaquette, P., Glasser, A.L., Huett, A., Xavier, R.J. \& DarfeuilleMichaud, A. Crohn's disease-associated adherent-invasive E. coli are selectively favoured by impaired autophagy to replicate intracellularly. Cell Microbiol. 12, 99-113 (2010).

72. Chervonsky, A.V. Influence of microbial environment on autoimmunity. Nat. Immunol. 11, 28-35 (2010).

73. Wu, H.J. et al. Gut-residing segmented filamentous bacteria drive autoimmune arthritis via T helper 17 cells. Immunity 32, 815-827 (2010).

74. Denning, T.L., Wang, Y.C., Patel, S.R., Williams, I.R. \& Pulendran, B. Lamina propria macrophages and dendritic cells differentially induce regulatory and interleukin 17-producing T cell responses. Nat. Immunol. 8, 1086-1094 (2007).

75. Mangan, P.R. et al. Transforming growth factor- $\beta$ induces development of the $T(H) 17$ lineage. Nature 441, 231-234 (2006).

76. Kimura, A. \& Kishimoto, T. IL-6: regulator of Treg/Th17 balance. Eur. J. Immunol. 40, 1830-1835 (2010).

77. Katsifis, G.E., Rekka, S., Moutsopoulos, N.M., Pillemer, S. \& Wahl, S.M. Systemic and local interleukin-17 and linked cytokines associated with Sjogren's syndrome immunopathogenesis. Am. J. Pathol. 175, 1167-1177 (2009).

78. Smith, P.D., Saini, S.S., Raffeld, M., Manischewitz, J.F. \& Wahl, S.M. Cytomegalovirus induction of tumor necrosis factor- $\alpha$ by human monocytes and mucosal macrophages. J. Clin. Invest. 90, 1642-1648 (1992).

79. Maheshwari, A. et al. Cytomegalovirus blocks intestinal stroma-induced down-regulation of macrophage HIV-1 infection. J. Leukoc. Biol. 80, 1111-1117 (2006).

80. Nathan, C.F. Secretory products of macrophages. J. Clin. Invest. 79, 319-326 (1987).

81. Schenk, M., Bouchon, A., Seibold, F. \& Mueller, C. TREM-1-expressing intestinal macrophages crucially amplify chronic inflammation in experimental colitis and inflammatory bowel diseases. J. Clin. Invest. 117, 3097-3106 (2007).

82. Zheng, H. et al. MYD88-dependent and -independent activation of TREM-1 via specific TLR ligands. Eur. J. Immunol. 40, 162-171 (2010).

83. Ford, J.W. \& McVicar, D.W. TREM and TREM-like receptors in inflammation and disease. Curr. Opin. Immunol. 21, 38-46 (2009).

84. Bleharski, J.R. et al. A role for triggering receptor expressed on myeloid cells- 1 in host defense during the early-induced and adaptive phases of the immune response. J. Immunol. 170, 3812-3818 (2003).

85. Schenk, M., Bouchon, A., Birrer, S., Colonna, M. \& Mueller, C. Macrophages expressing triggering receptor expressed on myeloid cells- 1 are underrepresented in the human intestine. J. Immunol. 174, 517-524 (2005).

86. Sharif, O. \& Knapp, S. From expression to signaling: roles of TREM-1 and TREM-2 in innate immunity and bacterial infection. Immunobiology 213, 701-713 (2008)

87. Naiki, Y. et al. Transforming growth factor- $\beta$ differentially inhibits MyD88-dependent, but not TRAM- and TRIF-dependent, lipopolysaccharide-induced TLR4 signaling. J. Biol. Chem. 280, 5491-5495 (2005).

88. Neurath, M.F. et al. Cytokine gene transcription by NF-кB family members in patients with inflammatory bowel disease. Ann NY Acad. Sci. 859, 149-159 (1998).

89. Rogler, G. et al. Nuclear factor kappaB is activated in macrophages and epithelial cells of inflamed intestinal mucosa. Gastroenterology 115, 357-369 (1998).

90. Chen, W., Frank, M.E., Jin, W. \& Wahl, S.M. TGF-beta released by apoptotic $T$ cells contributes to an immunosuppressive milieu. Immunity 14, 715-725 (2001).

91. Fadok, V.A., Bratton, D.L. \& Henson, P.M. Phagocyte receptors for apoptotic cells: recognition, uptake, and consequences. J. Clin. Invest. 108, 957-962 (2001)

92. Fadok, V.A. et al. Macrophages that have ingested apoptotic cells in vitro inhibit proinflammatory cytokines production through autocrine/ paracrine mechanisms involving TGF-B, PGE2, and PAF. J. Clin. Invest. 101, 890-898 (1998).

93. Wahl, S.M., Wen, J. \& Moutsopoulos, N. TGF-beta: a mobile purveyor of immune privilege. Immunol. Rev. 213, 213-227 (2006).

94. Chen, W. et al. Conversion of peripheral $C D 4^{+} C D 25^{-}$naive $T$ cells to $\mathrm{CD} 4{ }^{+} \mathrm{CD} 25^{+}$regulatory T cells by TGF- $\beta$ induction of transcription factor Foxp3. J. Exp. Med. 198, 1875-1886 (2003).
95. Qian, B.F. \& Wahl, S.M. TGF-beta can leave you breathless. Curr. Opin. Pharmacol. 9, 454-461 (2009).

96. Curotto de Lafaille, M.A. \& Lafaille, J.J. Natural and adaptive foxp3+ regulatory T cells: more of the same or a division of labor? Immunity 30 , 626-635 (2009).

97. Saruta, $\mathrm{M}$. et al. Characterization of $\mathrm{FOXP} 3^{+} \mathrm{CD} 4^{+}$regulatory T cells in Crohn's disease. Clin. Immunol. 125, 281-290 (2007).

98. Harris, P.R. et al. Helicobacter pylori gastritis in children is associated with a regulatory T-cell response. Gastroenterology 134, 491-499 (2008).

99. Manicassamy, S. et al. Activation of $\beta$-catenin in dendritic cells regulates immunity versus tolerance in the intestine. Science 329, 849-853 (2010).

100. Shen, R., Smythies, L.E., Clements, R.H., Novak, L. \& Smith, P.D. Dendritic cells transmit HIV-1 through human small intestinal mucosa. J. Leukoc. Biol. 87, 663-670 (2010).

101. Shen, R. et al. GP41-specific antibody blocks cell-free HIV type 1 transcytosis through human rectal mucosa and model colonic epithelium. J. Immunol. 184, 3648-3655 (2010).

102. Meng, G. et al. Primary intestinal epithelial cells selectively transfer R5 HIV-1 to CCR5 ${ }^{+}$cells. Nat. Med. 8, 150-156 (2002).

103. Alfsen, A., Yu, H., Magerus-Chatinet, A., Schmitt, A. \& Bomsel, M. HIV-1-infected blood mononuclear cells form an integrin- and agrin-dependent viral synapse to induce efficient HIV-1 transcytosis across epithelial cell monolayer. Mol. Biol. Cell 16, 4267-4279 (2005).

104. Shacklett, B.L. Immune responses to HIV and SIV in mucosal tissues: "location, location, location". Curr. Opin. HIV AIDS 5, 128-134 (2010).

105. Smit-McBride, Z., Mattapallil, J.J., McChesney, M., Ferrick, D. \& Dandekar, S. Gastrointestinal T lymphocytes retain high potential for cytokine responses but have severe $\mathrm{CD} 4^{+} \mathrm{T}$-cell depletion at all stages of simian immunodeficiency virus infection compared to peripheral lymphocytes. J. Virol. 72, 6646-6656 (1998).

106. Veazey, R.S. et al. Gastrointestinal tract as a major site of $C D 4^{+} \mathrm{T}$ cell depletion and viral replication in SIV infection. Science 280, 427-431 (1998).

107. Guadalupe, M. et al. Severe CD4+ $T$ cell depletion in gut lymphoid tissue during primary human immunodeficiency virus type 1 infection and substantial delay in restoration following highly active antiretroviral therapy. J. Virol. 77, 11708-11717 (2003).

108. Brenchley, J.M. et al. T-cell subsets that harbor human immunodeficiency virus (HIV) in vivo: implications for HIV pathogenesis. J. Virol. 78, 1160-1168 (2004).

109. Mehandru, S. et al. Primary HIV-1 infection is associated with preferential depletion of $\mathrm{CD} 4+\mathrm{T}$ lymphocytes from effector sites in the gastrointestinal tract. J. Exp. Med. 200, 761-770 (2004).

110. Li, Q. et al. Peak SIV replication in resting memory $\mathrm{CD} 4^{+} \mathrm{T}$ cells depletes gut lamina propria CD4+ $\mathrm{T}$ cells. Nature 434, 1148-1152 (2005).

111. Mattapallil, J.J. et al. Massive infection and loss of memory CD4 ${ }^{+}$T cells in multiple tissues during acute SIV infection. Nature 434, 1093-1097 (2005).

112. Mehandru, S. et al. Mechanisms of gastrointestinal CD4+ T-cell depletion during acute and early human immunodeficiency virus type 1 infection. J. Virol. 81, 599-612 (2007).

113. Li, L., Meng, G., Graham, M.F., Shaw, G.M. \& Smith, P.D. Intestinal macrophages display reduced permissiveness to human immunodeficiency virus 1 and decreased surface CCR5. Gastroenterology 116, 1043-1053 (1999).

114. Meng, G. et al. Lamina propria lymphocytes, not macrophages, express CCR5 and CXCR4 and are the likely target cell for human immunodeficiency virus type 1 in the intestinal mucosa. J. Infect. Dis. 182, 785-791 (2000).

115. Shen, R. et al. Macrophages in vaginal but not in intestinal mucosa are monocyte-like and permissive to HIV-1. J. Virol. 83, 3258-3267 (2009).

116. Kedzierska, K., Crowe, S.M., Turville, S. \& Cunningham, A.L. The influence of cytokines, chemokines and their receptors on HIV-1 replication in monocytes and macrophages. Rev. Med. Virol. 13, 39-56 (2003).

117. Gorry, P.R., Churchill, M., Crowe, S.M., Cunningham, A.L. \& Gabuzda, D. Pathogenesis of macrophage tropic HIV-1. Curr. HIV Res. 3, 53-60 (2005).

118. Carter, C.A. \& Ehrlich, L.S. Cell biology of HIV-1 infection of macrophages. Annu. Rev. Microbiol. 62, 425-443 (2008).

119. Orenstein, J.M. \& Wahl, S.M. The macrophage origin of the HIVexpressing multinucleated giant cells in hyperplastic tonsils and adenoids. Ultrastruct. Pathol. 23, 79-91 (1999). 


\section{REVIEW}

120. Wahl, S.M. et al. Macrophage- and astrocyte-derived transforming growth factor $\beta$ as a mediator of central nervous system dysfunction in acquired immune deficiency syndrome. J. Exp. Med. 173, 981-991 (1991).

121. Moutsopoulos, N.M., Greenwell-Wild, T. \& Wahl, S.M. Differential mucosal susceptibility in HIV-1 transmission and infection. Adv. Dent. Res. 19, 52-56 (2006).

122. Crowe, S.M. et al. The macrophage: the intersection between HIV infection and atherosclerosis. J. Leukoc. Biol. 87, 589-598 (2010).

123. Yadav, A. \& Collman, R.G. CNS inflammation and macrophage/ microglial biology associated with HIV-1 infection. J. Neuroimmune. Pharmacol. 4, 430-447 (2009).

124. Smith, P.D., Fox, C.H., Masur, H., Winter, H.S. \& Alling, D.W. Quantitative analysis of mononuclear cells expressing human immunodeficiency virus type 1 RNA in esophageal mucosa. J. Exp. Med. 180, 1541-1546 (1994).

125. Wahl, S.M., Greenwell-Wild, T. \& Vazquez, N. HIV accomplices and adversaries in macrophage infection. J. Leukoc. Biol. 80, 973-983 (2006).

126. Wahl, S.M. et al. Viral and host cofactors facilitate HIV-1 replication in macrophages. J. Leukoc. Biol. 74, 726-735 (2003).
127. Vazquez, N. et al. Human immunodeficiency virus type 1-induced macrophage gene expression includes the p21 gene, a target for viral regulation. J. Virol. 79, 4479-4491 (2005).

128. Bergamaschi, A. \& Pancino, G. Host hindrance to HIV-1 replication in monocytes and macrophages. Retrovirology 7, 31 (2010).

129. Peng, G. et al. Myeloid differentiation and susceptibility to HIV-1 are linked to APOBEC3 expression. Blood 110, 393-400 (2007).

130. Peng, G., Lei, K.J., Jin, W., Greenwell-Wild, T. \& Wahl, S.M. Induction of APOBEC3 family proteins, a defensive maneuver underlying interferon-induced anti-HIV-1 activity. J. Exp. Med. 203, 41-46 (2006).

131. Sheehy, A.M., Gaddis, N.C., Choi, J.D. \& Malim, M.H. Isolation of a human gene that inhibits HIV-1 infection and is suppressed by the viral Vif protein. Nature 418, 646-650 (2002).

132. Zheng, Y. et al. CD86 and CD80 differentially modulate the suppressive function of human regulatory T cells. J. Immunol. 172, 2778-2784 (2004).

133. Hyytiäinen, M., Penttinen, C. \& Keski-Oja, J. Latent TGF-beta binding proteins: extracellular matrix association and roles in TGF-beta activation. Crit. Rev. Clin. Lab. Sci. 41, 233-264 (2004). 